\title{
Numerical Study of Air-Flow Phenomena Through a Baffled Rectangular Micro-Channel
}

\author{
Sandip Saha \\ Department of Mathematics, NIT Silchar, Silchar-788010, Assam, India \\ E-mail:sandip.tfgss@gmail.com
}

Received: 29 April 2021; Accepted: 14 June 2021; Available online: 15 July 2021

\begin{abstract}
The aim of this study is to investigate the heat transfer characteristics of turbulent airflow phenomena in a rectangular micro-channel in presence of two plane shaped (type-1) and diamond shaped (type-2) baffles which will help to develop various heat exchanger models. Finite volume method has been used to solve the governing equations and the FLUENT software has been employed to visualize the simulation results. For both the baffles, the profile of flow structure, normalized velocity profile, normalized friction factor and average Nusselt number have been investigated with the variations of Reynolds number ranges between [10,000-50,000]. In terms of fluid flow and heat transfer phenomena, it has been found that in the presence of diamond shaped baffles (type2) are more convenient than plane shaped baffles.
\end{abstract}

Keywords: Rectangular micro-channel; Plane baffles; Diamond baffles; Turbulent airflow.

\section{Introduction}

Over the last few years, thermal efficiency of a flow has become one of the major issues in various engineering and scientific fields such as air conditioners, room coolers, chemical reactors, etc [1-7]. There are many mechanisms available to increase heat exchange in fluid media. A large number of authors [8-13] found that in the presence of baffles, the efficiency of heat transfer phenomena has become the most efficient mechanism and which baffles are mounted in the enclosure for increasing heat transfer and the rotation of enhancing turbulence.

In a rectangular micro-channel with two periodically mounted square baffles, Valencia et al. [14] numerically studied the turbulent air-flow and heat transfer phenomena using the standard k- $\varepsilon$ turbulence model and found that the presence of baffle causes the enhancement of heat transfer. In presence of solid and perforated baffles, Dutta et al. [15] investigated the enhancement of thermal characteristics in a rectangular micro-channel. In addition, the influence of baffle spacing, length and pitch of baffles were also investigated by Dutta et al. [16, 17]. Based on the experimental geometry of Dutta et al. [17], numerical studies on turbulent air-flow were performed by Saim et al. [18] using plane baffles for inclined angle $45^{\circ}$ and $60^{\circ}$. In a tube with circular baffles, Ozceyhan et al. [19] performed a numerical study on different characteristics of heat transfer phenomena. In a rectangular microchannel with pin shaped baffles, Wang et al. [20] numerically and experimentally studied the characteristics of heat transfer phenomena. By numerically and experimentally, Nanan et al. [21] made a comparative study on heat transfer characteristics in presence of typical straight baffles, straight cross-baffles, straight alternate-baffles, twisted-baffles, alternate twisted-baffles and twisted cross-baffles. Gholami et al. [22] numerically studied the laminar and forced flow and heat transfer of oil/multi-walled carbon nanotubes nanofluid in a micro-channel with ribs of the forms rectangular, oval, parabolic, triangular and trapezoidal for different values of $R e$ and volume fractions. The results of this work indicate that the existence of ribs enhances the friction factor and Nusselt number significantly. Among the ribs considered in this work, the parabolic rib, in respect of the augmentation of friction factor, has the best proportion of Nusselt number enhancement. Behnampour et al. [23] numerically investigated the effect of using rectangular, triangular and trapezoidal ribs on laminar heat transfer of water/AgO nanofluid flow for nanoparticles volume fractions of $0-4 \%$ in a rectangular micro-channel. They observed that the rectangular rib causes the maximum changes in velocity profile along the central line of flow and the triangular rib provides the best rate of thermal enhancement factor.

Akbari et al. [24] numerically studied the effect of change in the height of the rib on flow and laminar heat transfer of water $/ \mathrm{Al}_{2} \mathrm{O}_{3}$ nanofluid in a two-dimensional micro-channel. They figured out that, by increasing height of the rib, $R e$ and volume fraction of nanoparticles, the rate of heat transfer can be improved. The effect of rectangular rib on the laminar heat transfer of water $/ \mathrm{Al}_{2} \mathrm{O}_{3}$ nanofluid flow in a three-dimensional rectangular micro-channel has been studied by Akbari et al. [25]. In their work, it is demonstrated that by increasing Re, number of ribs and volume fraction of nanoparticles, the heat transfer on the heated surfaces can be improved. 
Karimipour et al. [26] simulated the effect of using rectangular rib on the forced heat transfer of water/Ag nanofluid in a rectangular micro-channel under the constant thermal boundary condition. They found that due to increase in volume fraction of nanoparticles and number of ribs, Nusselt number enhances significantly for higher Re. In a rectangular micro-channel with two plane baffles (alternately mounted on the walls), Demartini et al. [27] performed an experimental work on air flow phenomena only in presence of plane baffles. They observed that the vortex length increases with the increase of Reynolds number. For the inclined baffles, Nassiruddin et al. [28] studied the enhancement of heat transfer phenomena for various values of $R e$. They showed that the value of average Nusselt number increases with the increase of baffle height and presence of baffles increase average Nusselt number by nearly $70 \%$.

The current work is a modification and extension of the experimental research works performed by Demartini et al. [27], numerical work of Saha et al. [29] and Saha [30]. The work of Dermitini et al. [27] does not provide any kind of variation in terms of different baffle configurations and does not include the heat transfer phenomena. The above reasons motivated us to carry forward the present study. In this study, two plane baffles and two diamond shaped baffles have been considered to know the characteristics of flow phenomena and heat transfer. As per our knowledge, this type of modification and the variations of baffle configurations were not considered earlier. This study becomes very much helpful for various engineering communities and industries, to select suitable baffle configurations in terms of flow phenomena and different characteristics of heat transfer phenomena.

\section{Physical geometry}

Figure 1 present the physical geometry along with plane baffles (Fig. 1a) and diamond shaped baffles (Fig. 1b), where two baffles are alternately mounted on the micro-channel walls. In this work, flow is assumed to be viscous, steady, incompressible, Newtonian and body forces, effect of viscous dissipation and the radiation of heat transfer have been neglected [29].
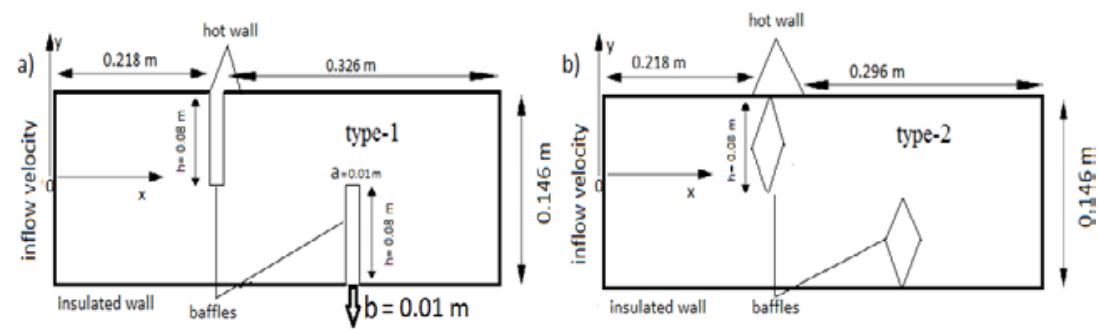

Figure 1. Rectangular micro-channel with plane baffles (a) and diamond shaped baffles.

\section{Governing equations of the problem geometry}

The present problem has been governed by the following continuity, momentum and energy equations [26-37].

$$
\begin{gathered}
\frac{\partial}{\partial \mathrm{x}_{\mathrm{i}}}\left(\rho u_{i}\right)=0 \\
\rho \frac{\partial}{\partial \mathrm{x}_{\mathrm{j}}}\left(u_{i} u_{j}\right)=-\frac{\partial \mathrm{p}}{\partial \mathrm{x}_{\mathrm{i}}}+\frac{\partial}{\partial \mathrm{x}_{\mathrm{j}}}\left[\mu\left(\frac{\partial u_{i}}{\partial \mathrm{x}_{\mathrm{j}}}-\rho \overline{u_{i} u_{j}}\right)\right] \\
\frac{\partial}{\partial \mathrm{x}_{\mathrm{j}}}\left(u_{i} T_{j}\right)=\frac{\partial}{\partial \mathrm{x}_{\mathrm{j}}}\left[\frac{\mu}{\operatorname{Pr}}\left(\frac{\partial u_{i}}{\partial \mathrm{x}_{\mathrm{j}}}-\rho \overline{u_{i} t_{j}}\right)\right]
\end{gathered}
$$

The parameters, $\rho$ and $\mu$ have been taken from the works of Dermitini et al. [27] and Saha et al. [29]. Here, $u_{i}, u_{j}$, p, $\rho \overline{u_{i} u_{j}}$ and $\rho \overline{u_{i} t_{j}}$ denoted as the components of mean velocity along $\mathrm{x}_{\mathrm{i}}$ and $\mathrm{x}_{\mathrm{j}}$ directions, pressure, Reynolds stresses and thermal stresses respectively. In 1975, Boussinesq introduced the following equation to characterize the Reynolds stresses.

$$
-\rho \overline{u_{i} u_{j}}=\mu_{t r}\left[\frac{\partial \bar{u}_{i}}{\partial \mathrm{x}_{\mathrm{j}}}+\frac{\partial \bar{u}_{j}}{\partial \mathrm{x}_{\mathrm{i}}}\right]-\frac{2}{3} \rho \delta_{i j} \mathrm{k}_{\mathrm{tr}}
$$


Where $\delta_{i j}, \mu_{t r}, \mathrm{k}_{\mathrm{tr}}$ denote the Kronecker delta, turbulent eddy viscosity (eq. 5) and turbulent kinetic energy (eq. 6) respectively with

$$
\begin{aligned}
\mu_{t r} & =\rho C_{\mu} \frac{\mathrm{k}_{\mathrm{tr}}^{2}}{\varepsilon_{\mathrm{tr}}} \\
k_{t r} & =\frac{1}{2} \overline{u_{i} u_{j}}
\end{aligned}
$$

Standard k- $\varepsilon$ turbulence model [30] has been used for the turbulence flow phenomena, which are given by

$$
\begin{gathered}
\rho\left(\frac{\partial}{\partial \mathrm{t}}\left(\mathrm{k}_{\mathrm{tr}}\right)+U_{j} \frac{\partial}{\partial \mathrm{x}_{\mathrm{j}}}\left(\mathrm{k}_{\mathrm{tr}}\right)\right)=\frac{\partial}{\partial \mathrm{x}_{\mathrm{j}}}\left[\left(\mu+\mu_{t r}\right) \frac{\partial}{\partial \mathrm{x}_{\mathrm{j}}}\left(\mathrm{k}_{\mathrm{tr}}\right)\right]+0.09-\rho \varepsilon_{\mathrm{tr}} \\
\rho\left(\frac{\partial}{\partial \mathrm{t}}\left(\varepsilon_{\mathrm{tr}}\right)+U_{j} \frac{\partial}{\partial \mathrm{x}_{\mathrm{j}}}\left(\varepsilon_{\mathrm{tr}}\right)\right)=\frac{\partial}{\partial \mathrm{x}_{\mathrm{j}}}\left[\left(\mu+\frac{\mu_{t r}}{1.3}\right) \frac{\partial}{\partial \mathrm{x}_{\mathrm{j}}}\left(\varepsilon_{\mathrm{tr}}\right)\right]+1.44 * \frac{\varepsilon_{\mathrm{tr}}}{\mathrm{k}_{\mathrm{tr}}} * 0.09-\rho * 1.92 * \frac{\varepsilon_{\mathrm{tr}}^{2}}{\mathrm{k}_{\mathrm{tr}}} \\
\text { Reynolds number }(R e)=\frac{\rho \bar{U} D_{h}}{\mu} \\
\text { friction factor }(f)=\frac{\left(\frac{\Delta p}{L}\right) D_{h}}{\frac{1}{2} \rho \bar{u}^{2}} \\
\text { local Nusselt number }\left(N u_{x}\right)=h_{x} \frac{D_{h}}{k_{f}} \\
\text { average Nusselt number }\left(N u_{\text {avg }}\right)=\frac{1}{0.554} \int N u_{x} \partial x \\
\text { normalized friction factor }(F)=\frac{f}{f_{0}} \\
\text { thermal enhancement factor, TEF }=\frac{N u}{N u_{0}} *\left(\frac{f_{0}}{f}\right)^{\frac{1}{3}}
\end{gathered}
$$

When, $R e \geq 10^{4}$, the value of $\mathrm{Nu}$ has been taken from the Dittus and Boelter correlation form [31], and the value of $\mathrm{f}_{0}$ taken from the Petukhov correlation form [32] when $3 \times 10^{3} \leq \operatorname{Re} \leq 5 \times 10^{6}$. Here, $\operatorname{Re}, D_{h}, \bar{U}, \tau_{w}$ and $\Delta p$ described as per Saha et al. [29-32].

Boundary conditions are as follows:

1) Boundary condition at Inlet section: $\mathrm{k}_{\mathrm{tr}}=0.005 u_{0}{ }^{2}, \varepsilon_{\mathrm{tr}}$ (inlet dissipation) $=0.1 \mathrm{k}_{\mathrm{tr}}{ }^{2}$ and $T_{\text {in }}=300 K$.

2) Boundary condition at outlet section:

$$
\frac{\partial}{\partial x}(\mathrm{u})=0, \frac{\partial}{\partial \mathrm{x}}\left(\mathrm{k}_{\mathrm{tr}}\right)=0 \text {, and } \frac{\partial}{\partial \mathrm{x}}\left(\varepsilon_{\mathrm{tr}}\right)=0 .
$$

3) Boundary condition at the boundary walls:

$$
\frac{\partial}{\partial \mathrm{n}}\left(\mathrm{k}_{\mathrm{tr}}\right)=0, \frac{\partial}{\partial \mathrm{n}}\left(\varepsilon_{\mathrm{tr}}\right)=0 \text {. }
$$

At upper wall $T_{w}=375 \mathrm{~K}$ and the lower wall is assumed to be thermally insulated.

\section{Results and discussions}

In this section, the characteristics of flow phenomena and thermal behavior have been presented in the form of graphs.

\subsection{Grid test and code validation}

In presence of two plane baffles and at $R e=87,300$, a grid independency test (fig. 2a) has been performed to assess the impact of grid sizes on the simulated results like Demartini et al. [27] and Saha et al. [29]. From the 
figure 2(b-c), it is cleared that 20,000 elements (Demartini et al. [27] and Saha et al. [29]) are sufficient to carry forward the present work.

\subsection{Flow phenomena}

At $R e=12000,48000$ velocity streamlines have been examined to know the impact of baffle configurations as shown in figures 3(a-d). It both the cases, it is observed that the flow field comes into contact with insulated wall due to the presence of the first baffle and velocity value becomes maximum at the top section of the second baffle. As a result, after the first baffle, the pressure values decreases and large length of vortex zone appears after the second baffle due to the low velocity. It has also been found that at the upstream section of the micro-channel absolute pressure drop attains its highest value and minimum value achieved at the downstream section of the micro-channel. It has also been observed that the length of recirculation zone increases with the increase of $R e$.

Table 1. Maximum velocity for various $R e$.

\begin{tabular}{cccc}
\hline \multicolumn{2}{c}{ Plane baffles (type-1) } & \multicolumn{2}{c}{ Diamond shaped baffles (type-2) } \\
\hline$R e$ & $\mathrm{x}=0.525 \mathrm{~m}$ & $R \mathrm{Re}$ & $\mathrm{x}=0.525 \mathrm{~m}$ \\
48000 & $17.4 \mathrm{~m} / \mathrm{s}$ & 48000 & $21.12 \mathrm{~m} / \mathrm{s}$ \\
\hline
\end{tabular}

a)
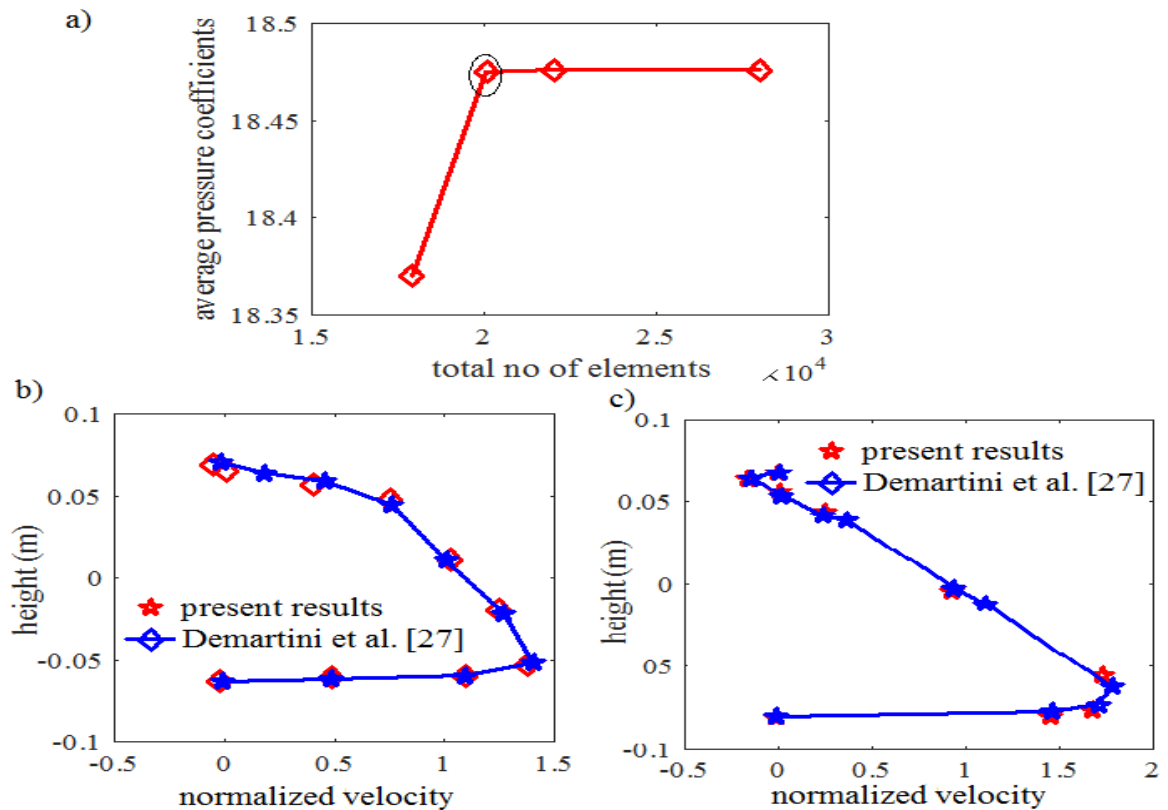

Figure 2. Variations of average pressure coefficients along hot wall (a) and dimensionless velocity profile at $\mathrm{x}=$ $0.159 \mathrm{~m}(\mathrm{~b}), \mathrm{x}=0.189 \mathrm{~m}(\mathrm{c})$.
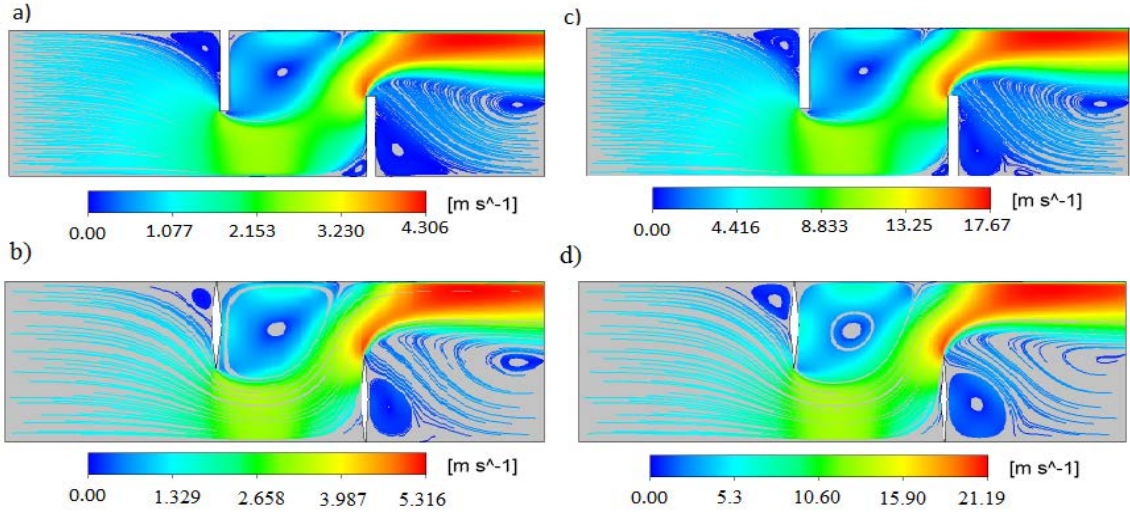

Figure 3. Velocity streamlines for $R e=12000$ (a, b) and $R e=48000$ (c, d) for type-1 (a) and type-2 configurations.

For both the cases, normalized velocity profiles have been presented in figure 4 for various values of $R e$ at fixed location $x=0.525 \mathrm{~m}$. It is found for the figures 3 and 4 that the velocity profiles become more enhanced in case of 
type-2 micro-channel than type- 1 micro-channel, which has been highlighted in table 1 . In addition, at $\mathrm{x}=0.525 \mathrm{~m}$ and at $R e=48,000$, it is calculated that the flow velocity becomes approximately 4.12 times and 5.23 times of reference velocity in case of type- 1 micro-channel and type- 2 channel respectively. Moreover, in case of type-2 micro-channel, maximum flow velocity becomes approximately 1.24 times of that type-1 micro-channel.

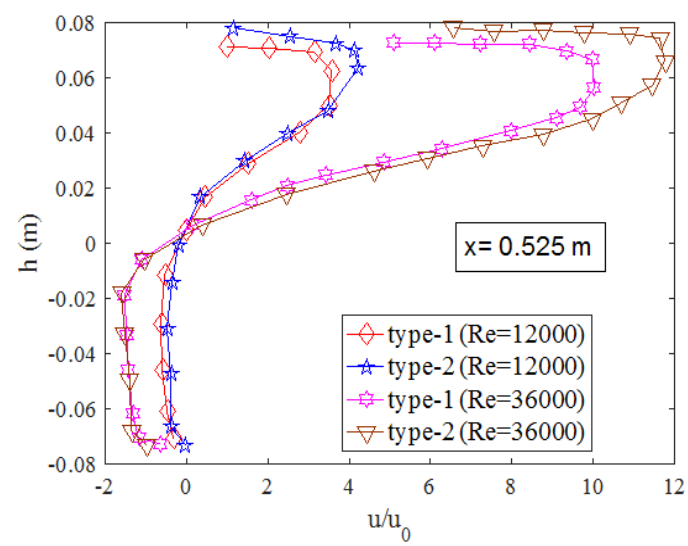

Figure 4. Normalized velocity profile at locations $\mathrm{x}=0.525 \mathrm{~m}$ for various $R e$.

\subsection{Thermal enhancement}

The change in heat transfer is related to the friction coefficient penalty, which causes the absolute pressure drop to increase. It is found that the maximum friction values in the intermediate zone between two baffles are attains due to the presence of the weak zone. In the region ahead of first baffle, it is investigated that the friction coefficient becomes negligible at the upstream of first baffle. At $R e=48000$, it has been concluded that in type-2, normalized friction factor (fig. 5a) becomes more enhanced than type-1.
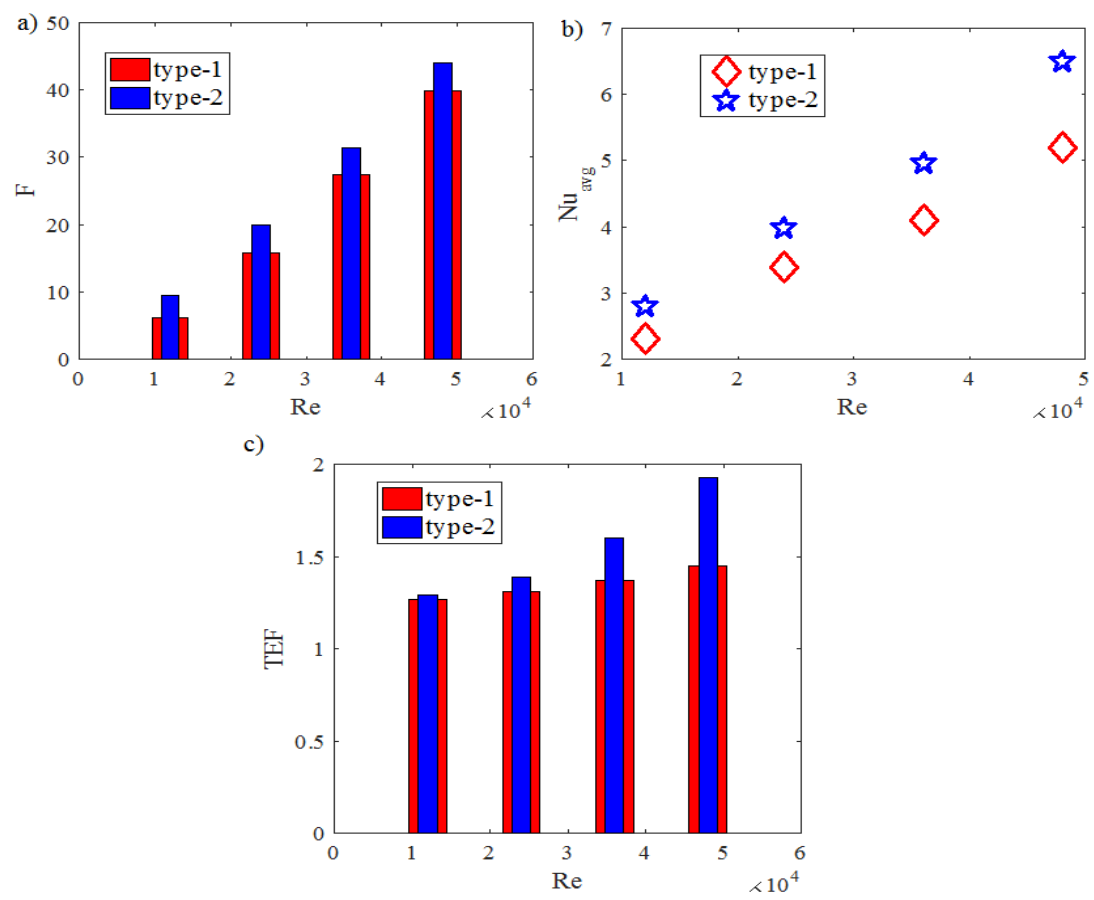

Figure 5. Variation of F (a), $N u_{\text {avg }}$ (b), and TEF (c) for different values of $R e$.

It has also been seen that the value of F, $N u_{a v g}$ and TEF increase with the increase of Re. Maximum values of the $N u_{\text {avg }}$ (fig. 5b) are seen after the second baffle due to the highest flow velocity. For both the cases, figure 5(c) present the profile of TEF for various values of Re. It has observed that the length of the recirculation zone becomes more significant because of the improvement in thermal gradient at peak velocity. In case of type- 2 micro-channel, it has also been found that the values of F; $N u_{\text {avg }}$ and TEF increase up to nearly 1.18, 1.37 times and $40 \%$ those in the case of type-1 micro-channel. 


\section{Conclusions}

A comparative study has been performed to study the different characteristics of turbulent airflow phenomena and thermal behavior in a rectangular micro-channel with two types of baffle configuration (Plane and diamond shaped baffles). The major conclusions have been prescribed as follows:

1) From the whole study, it has been concluded that in terms of maximum flow velocity, normalized friction factor, average Nusselt number and thermal enhancement factor become more pronounced in case of type 2 microchannel than type-1 micro-channel.

2) Further, it has been ensured that in terms of heat transfer, diamond shaped baffles (type-2) are more convenient as compared to the use of plane baffles (type-1).

For different engineering communities and industries, this research is very helpful in selecting which type of baffle configurations in terms of flow phenomena and different characteristics of heat transfer phenomena.

\section{References}

[1] Saha S, Biswas P, Nath S. Bifurcation phenomena for incompressible laminar flow in expansion channel to study Coanda effect. Journal of Interdisciplinary Mathematics. 2020; 23(2); 493-502.

[2] Saha S, Biswas P, Nath S. Numerical Modeling of Bifurcation and Leakage of Blood Flow in Mitral Valve to Predict Heart Malfunctioning. Springer LAIS Series. 2020; 684-692.

[3] Saha S, Biswas P, Raut S, Das N A. Convective heat transfer of laminar nano-fluids flow through a rectangular micro-channel with different types of baffle-corrugation. International Journal for Computational Methods in Engineering Science and Mechanics. 2021; 22(2).

[4] Saha S. A Survey on Flow Phenomena and Heat Transfer through Expansion Geometry. Lecture Notes in Mechanical Engineering. 2021; 202; 257-264.

[5] Saha S. Numerical Simulation of Turbulent Flow through a Sudden Expansion Channel: Comparison between Three Models. Lecture Notes in Mechanical Engineering. 2021; 202; 49-56.

[6] Saha S, Biswas P, Raut S, Das N A. Analysis of heat transfer characteristics through an rectangular enclosure. Materials Today Proceedings. 2021; https://doi.org/10.1016/j.matpr.2021.04.191.

[7] Saha S, Biswas P, Nath S. Numerical Simulation of Blocked Blood Vessel for Early Diagnosis of Coronary Artery Disease. Modeling, Simulation and Optimization. 2021; 206; 711-721

[8] Saha S, Das N A. Flow Bifurcation Phenomena of Shear-Thinning and Newtonian Fluids in a Rectangular Channel in Presence of Intermediate Steps: using Carreau-Yasuda Model. Journal of Applied Fluid Mechanics. 2021; 14(4); 1283-1293.

[9] Wilfried R, Deiying W L. Effect of baffle/shell leakage flow on heat transfer in shell-and-tube heat exchanger. Experimental Thermal and Fluid Science. 1994. 8: 10-20.

[10] Yang Y T, Hwang C Z. Calculation of turbulent flow and heat transfer in a porous-baffled channel. Int. J. Heat Mass Transfer. 2003; 46. 771-780.

[11] Lei Y G, He Y, Chu P, Li R. Design and optimization of heat exchangers with helical baffles. Chemical Engineering Science. 2008; 63, 4386-4395.

[12] Menter F R. Influence of free stream values on k-co turbulence model predictions. AIAA J. 1992; 30(6). 1657-1659.

[13] Molki M, Mostoufizadeh A R. Turbulent heat transfer in rectangular ducts with repeated-baffle blockages. Int. J. Heat Mass Transfer. 1989; 32. 1491-1499.

[14] Valencia A, Cid M. Turbulent unsteady flow and heat transfer in channels with periodically mounted square bars. International Journal of Heat and Mass Transfer. 2002; 45(8): 1661-1673.

[15] Dutta P, Hossain A. Internal cooling augmentation in rectangular channel using two inclined baffles. International Journal of Heat and Fluid Flow. 2005; 26 (2): 223-232.

[16] Dutta P, Dutta S. Effect of baffle size, perforation, and orientation on internal heat transfer enhancement. Int J Heat Mass Transf. 1989; 41: 3005-3013.

[17] Dutta S, Dutta P, Jones RE, Khan JA. Heat transfer coefficient enhancement with perforated baffles. ASME J Heat Transf. 1998; 120:795-797.

[18] Saim R, Bouchenafa R, Benzenine H, Oztop F H, Salem A K, Abboudi S. A computational work on turbulent flow and heat transfer in a channel with inclined baffles. Heat Mass Transfer. 2013; 49: 761-774.

[19] Ozceyhan V, Gunes S, Buyukalaca O, Altuntop N. Heat transfer enhancement in a tube using circular cross sectional rings separated from wall. Applied Energy. 2008; 85(10): 988-1001.

[20] Wang F, Zhang J, Wang S. Investigation on flow and heat transfer characteristics in rectangular channel with drop-shaped pin fins. Propulsion and Power Research. 2012; 1(1): 64-70. 
[21] Nanan K, Thianpong C, Pimsarn M, Chuwattanakul V, Eiamsaard S. Flow and thermal mechanisms ina heat exchanger tube inserted with twisted cross-baffle turbulators. Applied Thermal Engineering. 2017; 114: 130147.

[22] Behnampour A, Akbari O A, Safaei M R, Ghavami M, Marzban A, Shabani G A S, Zarringhalam M, Mashayekhi R. Analysis of heat transfer and nanofluid fluid flow in microchannels with trapezoidal,rectangular and triangular shaped ribs. Phys E. 2017; 91: 15-31.

[23] Akbari O A, Karimipour A, Toghraie D, Safaei M R, Alipour Goodarzi M H, Dahari M. Investigation of Rib's height effect on heat transfer and flow parameters of laminar water-Al2O3nanofluid in a two dimensional rib-microchannel. Appl Math Comp. 2016; 290: 135-153.

[24] Akbari O A, Karimipour A, Toghraie D, Karimipour A. Impact ofribs on flow parameters and laminar heat transfer of Water-Aluminum oxide nanofluid with different nanoparticle volume fractions in a threedimensional rectangular microchannel. Adv Mech Eng. 2016; 7: 1-11.

[25] Karimipour A, Alipour H, Akbari OA, Semiromi DT, Esfe MH. Studying the effect of indentation on flow parameters and slow heat transfer of water-silver nano-fluid with varying volume fraction in a rectangular two-dimensional microchannel. Indian J Sci Technol. 2016; 8(15): 1-13.

[26] Gholami R M, Akbari O A, Marzbani A, Toghraie D, Sheikh Shabani G A, Zarringhalam M. The effect of rib shape on the behavior of laminar flow of oil/MWCNT nanofluid in a rectangular microchannel. Journal of Thermal Analysis and Calorimetry. 2018; 134: 1611-1628

[27] Demartini L C, Vielmo H A, Möller S V. Numeric and experimental analysis of the turbulent flow through a channel with baffle plates. J Braz Soc Mech Sci Eng. 2004; 26:153-159.

[28] Nassiruddin M H, Siddiqui K. Heat transfer augmentation in a heat exchanger tube using a baffle. International Journal of Heat and Fluid Flow. 2007; 28(2): 318-328

[29] Saha S, Biswas P, Nath S, Singh L. Numerical simulations of Newtonian fluid flow through a suddenly contracted rectangular channel with two different types of baffle plates. Soft Computing. 2020; 24: 1-13.

[30] Saha S. Numerical simulation of turbulent airflow and heat transfer through a rectangular channel along with two trapezoidal baffle plates: comparison between plane and trapezoidal shape baffles plates. AIP Conference Proceedings. 2021; 2341: 1-10.

[31] Launder E B, Spalding D B. The Numerical Computation of Turbulent Flow. Computer Methods in Applied Mechanics and Engineering. 1974; 3(2): 269-289.

[32] Dittus F W, Boelter K M L. Heat transfer in automobile radiators of the tubular type. International Communications in Heat and Mass Transfer. 1985; 12(1): 3-22, 1985.

[33] Petukhov S V. Advances in heat transfer. academic press. New York. 1970; 6: 503-504.

[34] Somchai S, Pongjet, P. Numerical analysis of laminar heat transfer in a channel with diamond-shaped baffles. Int. Comm. Heat Mass Transfer. 2009; 36: 32-38.

[35] Webb B W, Ramadhyani S. Conjugate heat transfer in a channel with staggered ribs. Int. J. Heat Mass Transfer. 1985; 28: 1679-1687.

[36] Wilcox D C. Reassessment of the scale-determining equation for advance turbulence models. AIAA J. 1988; 26(11): 1299-1310.

[37] Oztop H F, Dagtekin I. Enhancement of heat transfer in a pipe with inner contraction-expansion-contraction pipe insertion. Int. Comm. Heat Mass Transfer. 2003; 30: 1157-1168.

(C) 2021 by the author(s). This work is licensed under a Creative Commons Attribution 4.0 International License (http://creativecommons.org/licenses/by/4.0/). Authors retain copyright of their work, with first publication rights granted to Tech Reviews Ltd. 